\title{
SISTEM SIMPAN TEMU KEMBALI INFORMASI DI \\ PERPUSTAKAAN MUHAMMADIAH DAN GRAMEDIA ATMO
}

PALEMBANG

\author{
Nabila Ainun Nazifah \\ Program Studi Ilmu Perpustakaan \\ Fakultas Adab dan Humaniora \\ Universitas Islam Negeri Raden Fatah Palembang \\ Email: nabilanazifah1998@gmail.com
}

\begin{abstract}
Abstrak
Sistem Simpan Temu Kembali yang dikenal dengan Information Retrival System merupakan sarana yang digunakan untuk memudahkan dalam penelusuran informasi secara cepat, tepat dan akurat. Banyak lembanga yang sudah menggunakan sistem dalam proses pengelolaan dan penyimpanan informasinya, yang mana hal ini bertujuan agar informasi tersebut nantinya dapat dengan mudah ditemukan oleh pengguna. Untuk itu didalam artikel ini akan dideskripsikan mengenai bagaimana Sistem Simpan Temu Kembali Informasi di Perpustakaan Muhammadiah Palembang dan di Gramedia Atmo Palembang, serta seperti apa perbandingan Sistem Simpan Temu Kembali Informasi di Perpustakaan Muhammadiah dan Gramedia Atmo Palembang. Metode yang digunakan dalam artikel ini adalah metode kualitatif dengan Teknik pengumpulan data dilakukan dengan observasi mengamati langsung dan wawancara kepada Staff pengelola perpustakaan Muhammadiah Palembang. Serta mengamati langsung keadaan di Gramedia Atmo. Kesimpulan dari artikel ini adalah Sistem Simpan Temu Kembali Informasi di Perpustakaan Muhammadiah belum baik, karena belum sesuai dengan standar yang ada, dikatakan demikian karena SSTKI di perpustakaannya dari desain tampilan visualnya belum userfriendly yang menyebabkan pemustaka atau pengguna kurang berminat menggunakan sarana tersebut karena belum memahami dan informasi yang ada di data SSTKI belum sesuai dengan data yang ada di rak buku, sehingga memperlambat dalam penelusuran dan penemuan informasi. Sedangkan di Gramedia Atmo Sistem Simpan Temu Kembali Informasinya banyak digunakan oleh pengunjung karena tampilan visualisasinya yang sederhana sehingga mudah dimegerti dan data yang ada di dalam SSTKI sesuai dengan keadaan data yang ada di rak buku atau koleksi. Dengan begitu dija dibandingkan kedua sistem Simpan Temu Kembali Informasi diantara ke dua tempat tersebut maka SSTKI di
\end{abstract}


Gramedia Atmo lebih baik, karena digunakan dan benar-benar termanfaat oleh pengunjung sudah berbasis Online.

Kata Kunci: Evaluasi Sistem Simpan Temu Kembali Informasi

\begin{abstract}
The Retrieval Save System, known as the Information Retrival System is a tool used to facilitate the search for information quickly, precisely and accurately. Many lembang have used the system in the process of managing and storing their information, which aims to make the information easily discoverable by users. For this reason, this article will describe how the Information Retrieval System in the Palembang Muhammadiah Library and the Gramedia Atmo Palembang, and what the comparison of the Information Retrieval System in the Muhammadiah and Gramedia Atmo Palembang Library is like. The method used in this article is a qualitative method with data collection techniques carried out by direct observation and interview to the library management staff Muhammadiah Palembang. As well as directly observing the situation at Gramedia Atmo. The conclusion of this article is the Information Retrieval System in the Muhammadiah Library is not good, because it is not in accordance with existing standards, it is said so because the SSTKI in the library from the visual display design is not user friendly yet which causes the user or user to be less interested in using the facility because they do not understand and the information in the SSTKI data does not match the data in the bookshelves, so that it slows down information searching and discovery. Whereas at Gramedia Atmo the Save Retrieval System is widely used by visitors because of its simple visualization display so that it is easy to understand and the data in SSTKI is in accordance with the state of the data that is on a bookshelf or collection. Thus compared to the two Save Information Retrieval systems between the two places, the SSTKI at Gramedia Atmo is better, because it is used and is truly benefited by visitors already online.
\end{abstract}

Keyword: System Evaluation Save Information Retrieval 


\section{A. PENDAhULUAN}

\section{LATAR BELAKANG}

Sistem temu kembali informasi berasal dari kata Information Retrieval System (IRS), dan biasa disebut dengan SSTKI dan berfungsi untuk menemukan informasi yang relevan dengan kebutuhan pemakai. ${ }^{18}$ Karena didalan SSTKI terdapat kegiatan Input - proses output. Dimana dalam hal ini out put yang dihasilkan akan bertujuan untuk memberikan kepuasan dan kemudahan seseorang dalam mencari informasi. Dalam SSTKI Chowdhury menyebutkan terdapat kegiatan yang lebih detail, yaitu: ${ }^{19}$

- Mengidentifikasi sumber-sumber informasi (dokumen) yang relevan dengan minat pemakai.

- Melakukan analisis isi dokumen.

- Mewakili isi dari sumber informasi sesuai dengan pertanyaan pemakai

- Melakukan analisis terhadap pertanyaan pemakai dan mewakilinya dalam bentuk yang cocok agar sesuai dengan database.

- Mencocokan istilah penelusuran dengan database.

- Menemukan kembali informasi yang relevan.

- Melakukan hal-hal yang perlu disesuaikan dalam sistem berdasarkan umpan balik (feedback) dari pemakai.

Berdasarkan kegiatan SSTKI yang dikemukakan oleh Chowdhury menunjukkan bahwa SSTKI sangatlah penting sekali didalam kehidupan sehari-hari terutama

\footnotetext{
${ }^{18}$ Putu L Pendit, Perpustakaan digital dari A-Z, (Jakarta: Cita Karyakarsa, 2008). hlm.18

${ }^{19}$ Sulistio Basuki, Pengantar Ilmu Perpustakaan, (Jakarta: Gramedia Pustaka, 1993), hlm. 17
} 
didalam sebuah lembaga / unit perpustakaan. tanpa adanya SSTI di perpustakaan maka pemustaka akan kesulitan dalam mencari informasi yang dibutuhkan. Begitu juga dengan pustakawan, apabila tidak adanya SSTKI di perpustakaan maka pustakawan akan kesulitan dalam melakukan kegiatan yang ada, terutama akan sulit dalam mendata dan mengumpulkan koleksi bahan pustaka yang agar nantinya mudah dan dapat ditemukan dengan cepat, tepat, dan akurat oleh pemustaka.

Sebagai contoh SSTKI yang ada diperpustakaan merupakan adanya OPAC, Katalog kartu, Indeks, Data base yang digunakan. Contoh tersebut merupakan penunjang dari terjalannya aktifitas didalam perpustakaan. dengan adanya SSTKI di perpustakaan maka dapat mengorganisasi dokumen agar mudah dan cepat diakses dengan kata lain menjembatani informasi dengan pengguna atau pemustaka yang membutuhkan informasi. Serta OPAC yang ada diperpustakaan biasanya tergolong kedalam SSTKI jenis In House yang dimana sistem ini membantu dalam pelayanan yang ada didalam Area Lokal yang dalam hal ini berarti OPAC hanya dapat diakses didalam ruangan saja, belum online.

Online Public Access Catalogue haruslah memiliki fasilitas-fasiltas yang meunjang mempermudah temu kembali informasi, dan haruslah memiliki desain tampilan yang User Friendly agar pemustaka atau pengguna dapat lebih mudah, faham, dan nyaman dalam menggunakan sarana temu kembali informasi yang disediakan. OPAC akan lebih baik apabila sudah 
mencangkup prinsip dan rekomendasi Guidelines for online public access catalogue yang dibentuk oleh IFLA (International Federation Of Library Associations and Institutions). 20

Dari penjelasan teori tersebut ketika penulis sedang berkunjung ke perpustakaan Muhammadiah Palembang terlihat bahwa sudah tersedianya sarana sistem simpan temu kembali informasi namun beberapa pemustaka atau pengguna terlihat tidak memanfaatkan sarana tersebut. Sedangkan di Gramedia Atmo, tersedianya sarana penelusur koleksi dan pengunjung sangat memanfaatkan sarana tersebut. Karena sebelum mereka mencari koleksi yang dibutuhkan atau yang ingin dibeli, mereka selalu mengecek terlebih dahulu disarana tersebut terkait ada atau tidaknya koleksi dan berapa harganya. Dengan begitu penulis tertarik ingin meneliti lebih mendalam lagi terkait hal ini, apakah pemustaka atau pengguna belum menyadari hadirnya sarana tersebut di perpustakaan. atau pula pemustaka kebingungan dalam mengoprasikan sarana tersebut yang memungkinkan tampilan desainnya yang membingungkan. Dan untuk pengunjung di Gramedia, penulis ingin mengetahui apakah sarana tersebut benarbenar termanfaatkan dengan baik. Berdasarkan hal ini maka penulis tertarik untuk melakukan penelitian dengan tema "Evaluasi Sistem Simpan Temu Kembali Informasi di Perpustakaan Muhammadiah dan Gramedia Atmo Palembang”.

${ }^{20}$ Doll W.J dan Torkzadeh, The Measurement of end - user computing satisfaction: theoretical connsideration, MIS Quarterly, hlm. 33 


\section{RUMUSAN MASALAH}

Dari latar belakang diatas, dapat diketahui bahwa cakupan permasalahan yang akan dibahas adalah:

a. Bagaimanakah Keadaan Sistem Simpan Temu Kembali Informasi di Perpustakaan Muhammadiah Palembang?

b. Bagaimanakah Keadaan Sistem Simpan Temu Kembali Informasi di Gramedia Atmo?

c. Seperti Apakah Perbandingan Sistem Simpan Temu Kembali Informasi di Perpustakaan Muhammadiah dan Gramedia Atmo Palembang?

\section{METODE PENELITIAN}

Penelitian ini menggunakan metode penelitian kualitatif deskriptif. Metode penelitian kualitatif melibatkan upaya - upaya penting, seperti mengajukan pertanyaan - pertanyaan dan prosedur - prosedur, mengumpulkan data yang spesifik dari para partisipan, menganalisa data, dan menafsirkan makna data. Metode penelitian deskriptif bertujuan untuk membuat deskripsi atau gambaran secara sistematis, faktual, dan akurat mengenai fakta - fakta, sifat - sifat hubungan antar fenomena yang diselidiki. Teknik pengumpulan data dilakukan dengan observasi mengamati langsung dan wawancara kepada Staff pengelola perpustakaan Muhammadiah Palembang. Serta mengamati langsung keadaan di Gramedia Atmo. Wawancara merupakan salah satu metode pengumpulan data dengan jalan komunikasi, yakni melalui kontak atau hubungan pribadi antara pengumpul data (pewawancara) dengan sumber data (responden). 


\section{B. PEMBAHASAN}

Sistem temu kembali informasi berasal dari kata Information Retrieval System (IRS). Temu kembali informasi adalah sebuah media layanan bagi pengguna untuk memperoleh informasi atau sumber informasi yang dibutuhkan oleh pengguna. Terdapat beberapa definisi sistem temu kembali informasi menurut para ahli di bidang ilmu perpustakaan dan informasi, yaitu: ${ }^{21}$

- Hougthon (1977) menjelaskan bahwa sistem temu kembali informasi adalah penelusuran yang merupakan interaksi antara pemakai dan sistem dan pernyataan kebutuhan pengguna diekspresikan sebagai suatu istilah tertentu.

- Sulistyo-Basuki (1991) mendefinisikan temu kembali informasi sebagai kegiatan yang bertujuan untuk menyediakan dan memasok informasi bagi pemakai sebagai jawaban atas permintaan atau berdasarkan kebutuhan pemakai.

Dari beberapa pengertian di atas, dapat disimpulkan bahwa sistem temu kembali informasi merupakan sistem informasi yang berfungsi untuk menemukan informasi yang relevan dengan kebutuhan pemakai. Karena didalan SSTKI terdapat kegiatan Input - proses - output. Dimana dalam hal ini out put yang dihasilkan akan bertujuan untuk memberikan kepuasan dan kemudahan seseorang dalam mencari informasi.

${ }^{21}$ Suzamkonyden dan Mikye Wijaya, Evaluasi sistem informasi perpustakaan UIN Suska berdasarkan organisasi: manajemen dan teknologi.(fakultas sains dan teknologi Riau Pekanbaru, 2012). HIm. 28 
Berdasarkan kegiatan SSTKI yang dikemukakan oleh Chowdhury menunjukkan bahwa SSTKI sangatlah penting sekali didalam kehidupan sehari-hari terutama didalam sebuah lembaga / unit perpustakaan. tanpa adanya SSTI di perpustakaan maka pemustaka akan kesulitan dalam mencari informasi yang dibutuhkan. Begitu juga dengan pustakawan, apabila tidak adanya SSTKI di perpustakaan maka pustakawan akan kesulitan dalam melakukan kegiatan yang ada, terutama akan sulit dalam mendata dan mengumpulkan koleksi bahan pustaka yang agar nantinya mudah dan dapat ditemukan dengan cepat, tepat, dan akurat oleh pemustaka. Contoh SSTKI yang ada diperpustakaan merupakan adanya OPAC, Katalog kartu, Indeks, Data base yang digunakan. Contoh tersebut merupakan penunjang dari terjalannya aktifitas didalam perpustakaan. dengan adanya SSTKI di perpustakaan maka dapat mengorganisasi dokumen agar mudah dan cepat diakses dengan kata lain menjembatani informasi dengan pengguna atau pemustaka yang membutuhkan informasi.

Dengan begitu disini penulis mencoba untuk mendeskripsikan keadaan sarana sistem temu kembali informasi di Perpustakaan Muhammadiah dan di Gramedia Atmo Palembang, yaitu sebagai berikut:

\section{a. Sistem Simpan Temu Kembali Informasi di Perpustakaan Muhammadiah Palembang}

Sarana sistem simpan temu kembali informasi di perpustakaan Muhammadiah Palembang banyak jenisnya, salah satunya adalah Online Public Access Catalogue / OPAC. Dalam hal SSTKI ini terdapat teori 
yang menjadi panutan dalam menerapkan kualitas desain tampilan yang baik untuk sistem SSTKI yaitu teori terkait Prinsip dan Rekomendasi Guidelines For Online Public Access Catalogue (OPAC). Displays Guidelines ini dikembangkan oleh Task Force on Guidelines for OPAC Displays, yang dibentuk oleh IFLA yang anggotanya terdiri dari 10 orang dan 6 komentator (reviewer).

Di dalam guideline ini terdiri dari prinsip dan rekomendasi yaitu, prinsip Guidelines ini adalah:22

- Pengutamaan kepada kebutuhan pengguna

- Pentingnya isi dan susunan cantuman untuk menemukan, mengidentifikasi, menyeleksi, dan mendapatkan bahan pustaka

- Perlunya untuk mengikuti isi dan struktur informasi yang telah diterima menjadi standar internasional.

Rekomendasi Guidelines ini adalah:23

- Desain tampilan seharusnya mengikuti guidelines dalam mendesain tampilan yang baik dan kriteria tampilan layar yang efektif karena hal ini semua berkaitan dengan legibility, clarity, understandibility dan navigability

${ }^{22}$ Mulla dan Chandrashekara, a study on the effective use of online public access catalogue at the libraries of engineering colleges in kamataka, International jurnal of library and information science Vol 1 (3), agust 2009. Hlm. 78

23 Ibid., 79 
- Desain tampilan seharusnya mengikuti tujuan katalog, sejauh hal ini merupakan suatu kodifikasi kebutuhan pengguna.

- Desain tampilan seharusnya mengikuti bahasa, sarana komunikasi yang digunakan oleh pengguna sehingga mereka dapat menemukan apa yang mereka inginkan dengan menggunakan kata-kata yang mereka kenal.

- Tampilan seharusnya cukup fleksibel untuk menyediakan kebutuhan pengguna yang berbeda, termasuk pengguna dengan kebutuhan khusus.

- Menampilkan apa yang diminta dan dibutuhkan untuk tindakan lebih lanjut.

- Menampilkan cantuman sesuai urutan yang bermakna, bukan random, ketika beberapa cantuman ditemukan.

- Tampilan seharusnya mendukung navigasi dari bagian-bagian informasi yang ditampilkan sampai kepada infor masi yang terkait

- Standar nasional dan internasional serta rekomendasirekomendasi yang diterima secara umum yang mempengaruhi tampilan OPAC yang harus diikuti.

Dari penjelasan diatas, maka teori tersebut dapat menjadi landasan dalam menilai kualitas dari desain tampilan sebuah sistem. Berdasarkan data yang penulis peroleh dari hasil wawancara dan observasi kepada staff pengelola perpustakaan dan pemustaka di perpustakaan Muhammadiah Palembang, terlihat bahwa di point pertama prinsip kebutuhan pengguna guidelines belum tersedia fasilitas bantuan / help. 
Tentang bagaimana cara penelusuran didalam OPAC tersebut, karena terdapat pemustaka yang masih belum mengetahui dalam menggunakan teknologi, dengan begitu maka membuat pemustaka enggan dalam menggunakan sarana SSTKI tersebut.

Serta dalam point kedua prinsip isi susunan, terlihat bahwa apa yang dibutuhkan pemustaka seperti informasi tentak letak buku, ketersediaan buku, dan data bibliografi buku sudah ada lengkap didalam point ini, dan juga menampilkan cantuman sesuai urutan yang bermakna, sehingga dalam point kedua ini nampak terlihat bahwa sarana OPAC sudah cukup User friendly. Dalam hal ini terlihat bahwa OPAC sebenarnya mudah digunakan dalam membantu penelusuran apabila dari pemustakanya sudah mendapatkan user education tentang penggunaan sarana SSTKI di perpustakaan serta manfaat, dan fungsi dari sarana tersebut.

Dengan begitu maka penulis menyimpulkan untuk desain tampilan sarana sistem simpan temu kembali informasi di Perpustakaan Muhammadiah Palembang belum sesuai menyeluruh dengan teori yang dikeluarkan oleh IFLA sebagaimana yang sudah dijelaskan diatas, namun keadaan desain tampilan SSTKI saat ini sudah cukup user fiendly terhadap pemustaka dan kualitas dari sistem tersebut juga yang ada di OPAC juga terkadang tidak sesuai dengan kondisi yang ada didalam rak-rak buku di perpustakaan. karena ketika penulis mencoba untuk menggunakan sarana tersebut, penulis langsung 
mencoba menelusuri buku filsafat umum dan didalam sarana tersebut tertampil bahwa buku tersebut ada dan berada dikelas 100, namun saat ditelusuri ternyata buku tersebut tidak ditemukan di lokasi rak yang dimaksudkan. Dan koleksi yang ada di rak tersebut untuk sususanan cukup tidak rapi karena urutan notasi dari satu buku ke buku yang lain belum sesuai. Dan kadang terdapat beberapa buku yang bukan kelas 100 berada di rak kelas tersebut. Berikut adalah beberapa dokumentasi yang didapat dari hasil observasi di perpustakaan Muhammadiah Palembang:

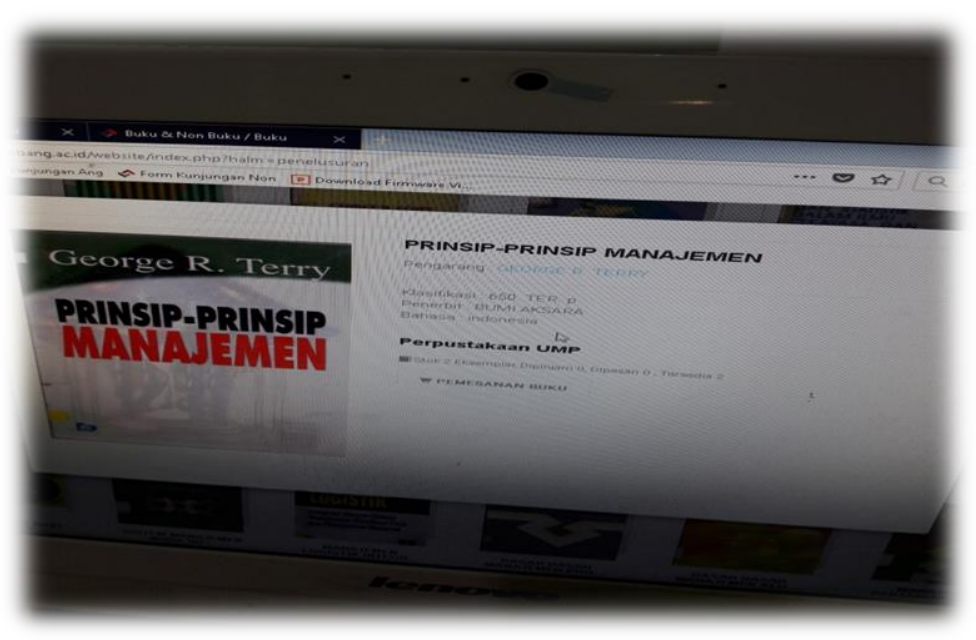




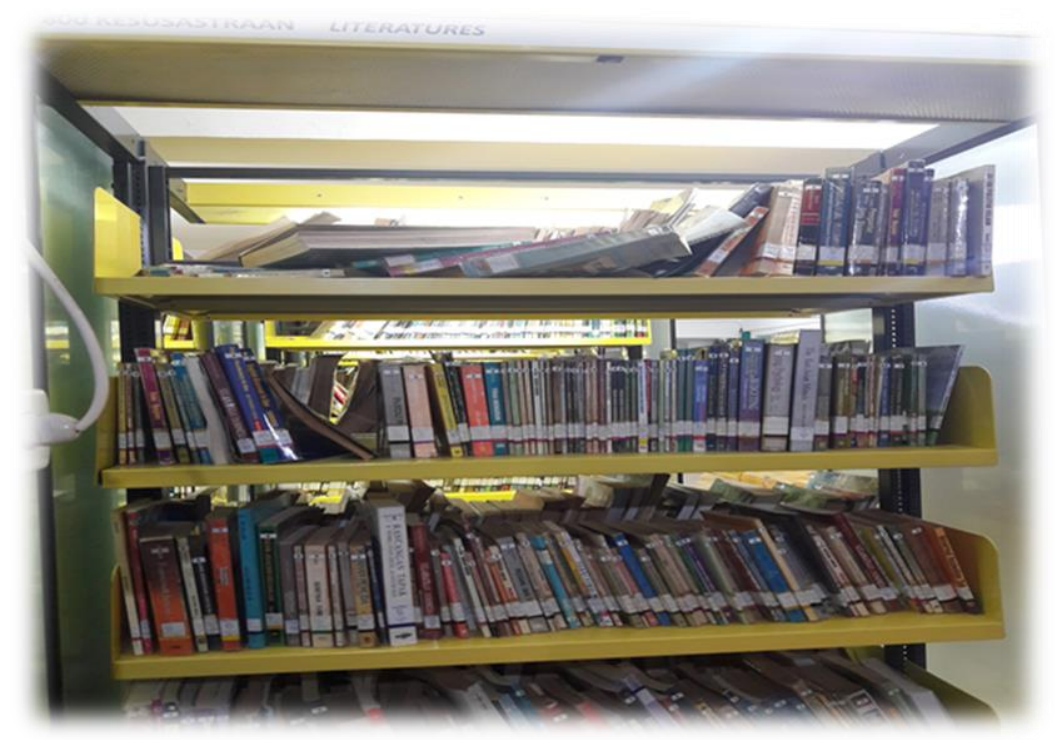

Berdasarkan data-data tersebut penulis mengambil kesimpulan bahwa sarana sistem simpan temu kembali informasi yang ada di Perpustakaan Muhammadiah belum cukup baik, namun sudah termanfaatkan oleh beberapa pengguna atau pemustaka. Dikatakan demikian karena terdapat beberapa poin yang belum sesuai dengan standar SSTKI, yang dimana SSTKI yang baik dan benar adalah ketika sebuah informasi dikelola dengan baik dan disimpan dengan baik, sehingga ketika proses temu kembalinya dapat dengan cepat, tepat, dan akurat. Dengan begitu maka akan membuat pemustaka atau pengguna merasa terbantu dengan adanya sarana tersebut, dan yang pastinya adalah agar terwujudnya sebuah sistem yang efektif dan efesian.

\section{b. Sistem Simpan Temu Kembali Informasi di Gramedia} Atmo 
Gramedia merupakan toko buku yang sudah berdiri sejak 2 februari 1970, dan toko ini bekerja sama dengan penerbit-penerbit buku baik dalam maupun luar negri. Dari kelompok usahanya sendiri, pemasok ke toko buku gramedia antara lain adalah Gramedia pustaka utama, Alex media Komputindo, Gramedia World, dll. Yang dalam hal ini penulis akan mendeskripsikan hasil penelitian di Gramedia Atmo Palembang. Gramedia yang merupakan toko buku ini tentunya menyimpan dan mengelola banyak sekali informasi yang ada, baik berupa buku pembelajaran, novel, dll. Yang dimana semua koleksi tersebut haruslah di kelola dengan baik agar dapat di layankan kepada pengunjung dan calon pembeli buku tersebut dengan cepat, tepat, dan akurat.

Di Gramedia ini menggunakan sebuah sistem sarana temu kembali informasi yang baik, yang dimana sistem ini sudah berbasis Online jadi dapat dikunjungi websitenya di Gramedia langsung, ataupun diakses di media elektronik manapun dan kapan pun waktunya tanpa terbatas asal memiliki jaringan internet yang cepat dan terkoneksi. Sistem dapat dinilai baik atau tidaknya melalui standar sebuah teori. Dalam hal ini sebuah sistem dapat dikatakan baik apabila sistem tersebut mudah digunakan, dimengerti dan cepat diakses. Sarana temu kembali informasi di Gramedia ini disediakan bertujuan untuk memudahkan pengunjung dalam mencari koleksi buku yang di inginkan. Dan didalam informasi tersebut tercakup data-data dari buku tersebut, seperti nama pengarang, judul, harga buku, nomor buku, dll. Dimana hal ini sangatlah bermanfaat 
untuk pengetahuan awal pengunjung ketika ingin mencari sebuah koleksi buku.

Sistem sarana temu kembali informasi yang ada di Gramedia Atmo ini memiliki tampilan visualisasi yang sederhana, user friendly, dan memiliki jaringan koneksi yang baik. dalam hal ini pengunjung ketika menggunakan sarana ini tidak merasa kebingungan karena tidak memasukkan nama pengarang / judul lalu menekan enter. Maka langsung akan tampil detail dari sebuah koleksi yang dicari atau dibutuhkan. Tampilan layar awalnya memang cukup tidak menarik karena tidak ada variasi warna ataupun desain-desain tersendiri. Tampilannnya hanyalah tulisan dan beberapa kolom biasa yang sederhana dan memudahkan pengunjung. Selain itu SSTKI di Gramedia ini mencangkup informasi yang sesuai dengan keadaan buku yang juga sesuai dengan tempat rak buku yang ada. Dengan begitu maka informasi yang ada di sarana tersebut sangatlah relevansi.

Relevansi informasi tersebut penulis yakinkan, karena penulis langsung mencoba menelusur informasi yang ada di sarana tersebut dan langsung mencoba mencari koleksi yang dibutuhkan, dan penulis sangatlah mudah dalam menemukan buku yang dibutuhkan karena sesuai dengan pembagian rak-rak yang ada, serta nomor bukunya pun sesuai. Berikut adalah beberapa dokumentasi yang menunjukkan kerelevansian data di sarana sistem simpan temu kembali informasi di Gramedia Atmo: 

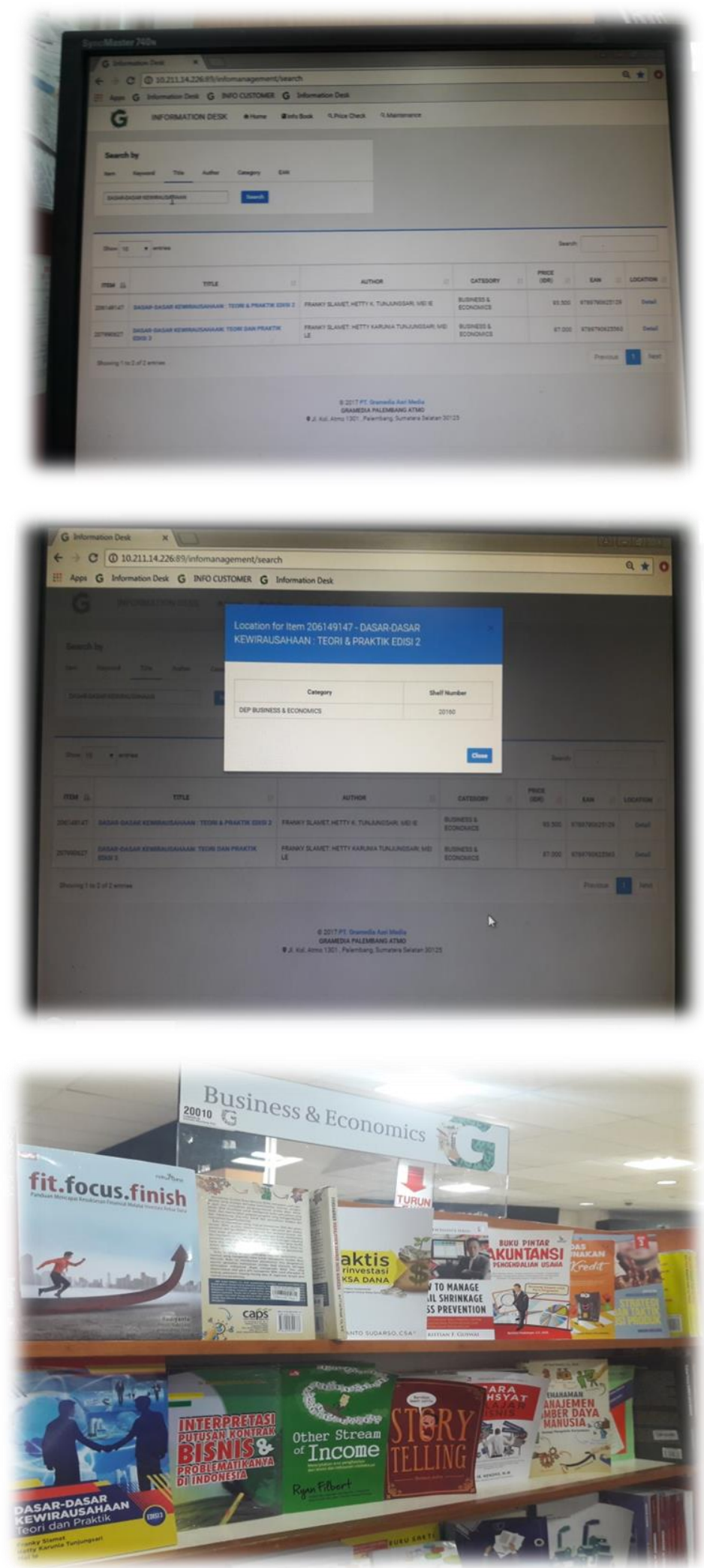

Berdasarkan data-data yang penulis peroleh maka menurut menulis SSTKI di Gramedia Atmo sudah baik, 
sehingga dapat membuat pengunjung dapat mengakses koleksi yang dibutuhkan dengan cepat, tepat, dan akurat.

\section{c. Perbandingan SSTKI di Perpustakaan Muhammadiah}

\section{Palembang dengan SSTKI di Gramedia Atmo}

Berdasarkan observasi dan wawancara yang penulis lakukan di ke dua tempat tersebut, maka penulis mencoba membandingkan diantara keduanya dari segi desain tampilan visual dan relevansi data antara data di SSTKI dengan keadaan di rak-rak buku yang disediakan. Dengan begitu maka perbandingan yang penulis dapatkan adalah Sistem Simpan Temu Kembali informasi yang ada di Gramedia Atmo cukup lebih baik dari pada yang ada di Perpustakaan Muhammadiah Palembang, karena dalam hal ini data yang ada di SSTKI Gramedia Atmo sesuai dengan data di Rak buku, sehingga dapat dengan cepat, tepat, dan akurat dalam penemuan koleksinya. Sedangkan di perpustakaan Muhammadiah cukup lama karena tidak tersusun rapi dan sesuai. Begitu pula di desain tampilan visualisasinya, di Gramedia Atmo Lebih sederhana sehingga User Friendly dibandingkan dengan desain tampilan visualisasi di SSTKI yang ada di Perpustakaan Muhammadiah Palembang.

\section{PENUTUP}

\section{KESIMPULAN}

Kesimpulan yang didapat dari hasil observasi di Perpustakaan Muhammadiah Palembang dan Gramedia 
Atmo adalah Sistem Simpan Temu Kembali Informasi di Perpustakaan Muhammadiah belum baik, karena belum sesuai dengan standar yang ada, dikatakan demikian karena SSTKI di perpustakaannya dari desain tampilan visualnya belum userfriendly yang menyebabkan pemustaka atau pengguna kurang berminat menggunakan sarana tersebut karena belum memahami dan informasi yang ada di data SSTKI belum sesuai dengan data yang ada di rak buku, sehingga memperlambat dalam penelusuran dan penemuan informasi. Sedangkan di Gramedia Atmo Sistem Simpan Temu Kembali Informasinya banyak digunakan oleh pengunjung karena tampilan visualisasinya yang sederhana sehingga mudah dimegerti dan data yang ada di dalam SSTKI sesuai dengan keadaan data yang ada di rak buku atau koleksi. Dengan begitu dija dibandingkan kedua sistem Simpan Temu Kembali Informasi diantara ke dua tempat tersebut maka SSTKI di Gramedia Atmo lebih baik, karena digunakan dan benar-benar termanfaat oleh pengunjung sudah berbasis Online. 


\section{DAFTAR PUSTAKA}

Doll W.J dan Torkzadeh. 1991. The Measurement of end user computing satisfaction: theoretical connsideration. MIS Quarterly.

Putu Laxman Pendit. 1993. Perpustakaan Digital dari A-Z. Jakarta: Cita Karyakarsa.

Sulistio Basuki. 1993. Pengantar Ilmu Perpustakaan. Jakarta: Gramedia Pustaka.

Suzamkonyden dan Mikye Wijaya. 2012. Evaluasi sistem informasi perpustakaan UIN Suska berdasarkan organisasi: manajemen dan teknologi.ffakultas sains dan teknologi Riau Pekanbaru. Fakultas sains dan teknologi Riau Pekanbaru. 